\title{
Human Tissue-type Plasminogen Activator Releases Fibrinopeptides A and B from Fibrinogen
}

Jeffrey I. Weitz, Moira K. Cruickshank, Bruce Thong, Beverly Leslie, Mark N. Levine, Jeffrey Ginsberg, and Thomas Eckhardt Department of Medicine, McMaster University and Hamilton Civic Hospitals Research Centre, Hamilton, Ontario, Canada

\section{Abstract}

In five patients with venous thromboembolic disease treated with recombinant tissue-type plasminogen activator (rt-PA), there was a marked increase in the mean concentrations of fibrinopeptide $A$ (from 0.6 to $5.9 \mathrm{nM} ; P<0.0001$ ) and desarginine fibrinopeptide $B$ (from 5.6 $\mathrm{nM}$ to $24.1 \mathrm{nM} ; P<0.01$ ) 30 min after a bolus of rt-PA $(0.6 \mathrm{mg} / \mathrm{kg})$. Thrombin was unlikely to be responsible because the levels of desarginine fibrinopeptide $B$ exceeded those of fibrinopeptide $A$ and the changes occurred despite concomitant heparin therapy. The purpose of this study therefore, was to determine whether rt-PA directly releases the fibrinopeptides from fibrinogen. Incubation of rt-PA with heparinized plasma or purified fibrinogen resulted in time and dose-dependent release of both fibrinopeptide $A$ and $B$. Contaminating thrombin was not responsible for this activity by the following criteria: the rate of rt-PA mediated fibrinopeptide $B$ release was considerably faster than that of fibrinopeptide A, and fibrinopeptide release was unaffected by heparin, hirudin, or a monospecific antithrombin IgG. Aprotinin also had no effect on fibrinopeptide release, indicating that this activity was not plasmin mediated. Fibrinopeptide release was shown to be due to rt-PA because this activity was completely blocked by a monoclonal antibody against the enzyme. Further, the specificity of rt-PA for the thrombin cleavage sites on fibrinogen was confirmed by the demonstration that rt-PA released fibrinopeptide $A$ or fibrinopeptide $B$ from fibrinopeptide A or B-containing substrates, respectively. These studies thus demonstrate that $(a)$ rt-PA releases fibrinopeptides $A$ and $B$ from fibrinogen thereby indicating that this enzyme is not specific for plasminogen, and (b) plasma fibrinopeptide $A$ and desarginine fibrinopeptide $B$ levels are not specific markers of thrombin action on fibrinogen in patients receiving rt-PA.

\section{Introduction}

Tissue-type plasminogen activator (t-PA $)^{1}$ is a trypsinlike serine proteinase that activates plasminogen to plasmin thereby

Presented in part at the 29th Annual Meeting of the American Society of Hematology, Washington, DC (1987. Blood. 70:411a. Abstr.) and the 45th National Meeting of the American Federation for Clinical Research, Washington, DC (1988. Clin. Res. 36:422a. Abstr.).

Address reprint requests to Dr. Weitz, Henderson General Hospital, 711 Concession Street, Hamilton, Ontario L8V 1C3, Canada.

Received for publication 14 December 1987 and in revised form 27 May 1988.

1. Abbreviations used in this paper: EACA, epsilon-amino caproic acid; desarginine FPB, desarginine fibrinopeptide B (B $11-13$ ); FPA, fibrino-

J. Clin. Invest.

(C) The American Society for Clinical Investigation, Inc.

$0021-9738 / 88 / 11 / 1700 / 08 \$ 2.00$

Volume 82, November 1988, 1700-1707 initiating fibrinolysis. Amounts of t-PA sufficient for clinical investigation have recently been produced in melanoma cell culture and by recombinant DNA techniques (rt-PA). Despite its affinity for fibrin $(1,2)$ and its enhanced enzymatic activity in the presence of this substrate $(3,4)$, initial clinical studies in patients with acute myocardial infarction have demonstrated that t-PA administration is associated with a significant decrease in the plasma fibrinogen concentration (5-9). These findings are not unexpected since theoretical calculations based on the reported kinetic parameters for the interaction between plasminogen and t-PA predicted that large doses of $t$-PA would result in systemic fibrinogenolysis $(10,11)$.

In addition to fibrinogenolysis, a troublesome complication of thrombolytic therapy for acute myocardial infarction is early rethrombosis (12-15) that can occur despite heparin (14, 15), aspirin, or dipyridamole administration (15). The etiology of reocclusion is unclear although high grade residual stenosis may be a contributing factor (16). To determine the role of activation of the coagulation system in rethrombosis, investigators have measured plasma levels of fibrinopeptide A (FPA) after thrombolytic therapy as an index of in vivo thrombin activity. Based on the observation that plasma FPA levels increase after the administration of rt-PA or streptokinase, it has been hypothesized that thrombolytic therapy is associated with thrombin generation and that this contributes to the rethrombosis $(17,18)$. Further, Owen et al. (18) concluded that thrombin produced in association with lytic therapy is generated at a site where it is protected from fluid-phase inhibitors since these investigators documented an increase in plasma FPA levels despite heparin administration. An alternate (and not mutually exclusive) explanation for these findings is that thrombolytic agents exert a direct effect on fibrinogen that results in fibrinopeptide release. This latter possibility is important not only because of its basic biochemical implications, but also because, if correct, it would put in question the validity of employing plasma FPA levels during thrombolytic therapy as a marker of thrombin activity.

In this study, patients with venous thromboembolic disease were treated with rt-PA. Despite concomitant heparin administration, rt-PA infusion was associated with a marked elevation in the plasma levels of both FPA and desarginine fibrinopeptide B (FPB). Further, at each time point the levels of desarginine FPB exceeded those of FPA. Thrombin was unlikely to be responsible for the increase in peptide levels because the pattern of changes is not characteristic of thrombin action on fibrinogen $(19,20)$, and because the changes occurred despite therapeutic doses of heparin. To explore the mechanism responsible for the increase in fibrinopeptide values, further experiments were performed to determine whether rt-PA has a direct effect on fibrinogen that results in fibrinopeptide release.

peptide A (A $\alpha 1-16)$ or B (B $\beta 1-14)$; rt-PA, recombinant human tissuetype plasminogen activator; $t-P A$, tissue-type plasminogen activator. 


\section{Methods}

Reagents. Two preparations of human rt-PA were employed. Both consisted of predominantly single-chain material. The rt-PA administered to patients and used in the majority of our experimental studies was obtained from Genentech, Inc., San Francisco, CA (lot K9051A6), and was cloned in a Chinese hamster ovarian cell line. The other rt-PA preparation (lot 118) was a gift from CODON, Inc., San Francisco, CA and was purified from a human melanoma cell line derived from RPMI 7932 that had been genetically modified to contain several copies of t-PA coding DNA. Unless otherwise stated, the rt-PA employed was the material produced by Genentech, Inc. Single-chain human melanoma cell t-PA (lot 28-04) and ESP 2, a monoclonal antibody against t-PA that has previously been shown to bind to t-PA and to inhibit its amidolytic and fibrinogenolytic activity (21), were from American Diagnostica, Greenwich, CT. PMSF and D-Phe-Pro$\mathrm{ArgCH}_{2} \mathrm{Cl}$ were from Sigma Chemical Co., St. Louis, MO, while aprotinin was from FBA Pharmaceuticals, New York. Human $\alpha$-thrombin was a generous gift of Dr. J. Fenton, II, NY State Department of Health, Albany, NY.

A monospecific polyclonal sheep IgG against human thrombin was provided by Dr. F. Ofosu, McMaster Medical Centre, Hamilton, Ontario. Preliminary studies with this antibody demonstrated that at a concentration of $5 \mu \mathrm{g} / \mathrm{ml}$ it inhibited $>98 \%$ of the FPA and FPB released from fibrinogen $(0.6 \mathrm{mg} / \mathrm{ml})$ by human $\alpha$-thrombin (at concentrations ranging from 0.01 to $0.2 \mathrm{U} / \mathrm{ml}$ ). The synthetic peptide analogues of FPA (A $\alpha 1-15, A \alpha 1-14, A \alpha 1-13$, and $A \alpha 1-12)$ and of the $\mathrm{NH}_{2}$-terminal region of the $A \alpha$-chain of fibrinogen (A $\alpha 1-18, A \alpha 1-19$, A $\alpha 1-22, A \alpha 1-23$, and A $\alpha 1-28$ ) were synthesized by $R$. Mumford of Merck Sharp and Dohme Research Laboratories, Rahway, NJ, using the solid-phase method of Merrifield (22). A $\alpha 1-20$ and A $\alpha 1-21$ were synthesized by Dr. G. Wilner, Washington University, St. Louis, as previously described (23).

Patients. After informed signed consent was obtained, five patients with angiographically documented pulmonary embolism and one patient with venographically confirmed axillary vein thrombosis were entered into a study of bolus dose rt-PA infusion. This study was approved by the Research Advisory Committees at the Hamilton Civic Hospitals and McMaster University.

All patients received an intravenous bolus of heparin $(5,000 \mathrm{U})$ followed by a continuous heparin infusion at $1,200 \mathrm{U} / \mathrm{h}$. The heparin dose was adjusted to maintain the activated partial thromboplastin time in the therapeutic range (1.5 to 2 times control). Once radiographic confirmation of venous thromboembolic disease was obtained, five of the six patients were given a single dose of rt-PA $(0.6 \mathrm{mg} / \mathrm{kg}$ ideal body wt reconstituted in $50 \mathrm{ml}$ sterile water) by bolus injection over 2 min and were monitored closely for evidence of bleeding. An additional patient with angiographically documented pulmonary embolism was treated with two bolus injections of rt-PA $(25 \mathrm{mg} /$ dose $)$ given $2 \mathrm{~h}$ apart. In all patients, the heparin infusion was continued throughout and was interrupted only for the 2-min interval(s) of rt-PA administration.

Blood collection and processing. Using a 21 -gauge butterfly needle, blood samples were collected from an antecubital vein immediately before rt-PA injection and at $0.5,1.5$, and $3.0 \mathrm{~h}$ after the infusion. At each time point, blood was drawn into $5-\mathrm{ml}$ vacutainer tubes (Becton Dickinson Co., Toronto, Ontario) prefilled with $50 \mu \mathrm{l}$ of D-Phe-ProArgCH $\mathrm{H}_{2} \mathrm{Cl}(100 \mu \mathrm{M}$ diluted in $1 \mathrm{mM} \mathrm{HCl})$. After careful mixing, $4.5 \mathrm{ml}$ of blood was transferred into a second tube containing $0.5 \mathrm{ml}$ of an anticoagulant solution consisting of $1,000 \mathrm{U} / \mathrm{ml}$ aprotinin, $1,400 \mathrm{U} / \mathrm{ml}$ heparin, $10 \mathrm{mM}$ adenosine, and $20 \mathrm{mM}$ theophylline in Hepes-buffered saline, $\mathrm{pH} 7.4$. The red cells were then sedimented by centrifugation at $1,700 \mathrm{~g}$ for $15 \mathrm{~min}$ at $4^{\circ} \mathrm{C}$ and the plasma was harvested. Within $30 \mathrm{~min}$ of blood collection the fibrinogen in $2 \mathrm{ml}$ plasma was precipitated by the addition of $6 \mathrm{ml}$ ethanol followed by centrifugation at $4,000 \mathrm{~g}$ at $4^{\circ} \mathrm{C}$ for $20 \mathrm{~min}$. The ethanol supernatants were evaporated to dryness in a Speed Vac Concentrator (Savant Instruments, Farmingdale, NY), reconstituted to original volume with distilled water and assayed for FPA and desarginine FPB immunoreactivity, as described below.

Radioimmunoassays. FPA was assayed as previously described (24). Antiserum R2, employed throughout these studies, has previously been shown to be specific for FPA and to crossreact poorly with fibrinogen or FPA-containing fragments from the $\mathrm{NH}_{2}$-terminal region of the A $\alpha$-chain of fibrinogen (25-27). FPB was quantified as described elsewhere (20) using antiserum R28. In plasma however, there is rapid loss of FPB immunoreactivity when measured with R28 (28) as a result of carboxypeptidase-mediated cleavage of $\operatorname{Arg}(B \beta 14)$. Accordingly, FPB cannot be measured directly but can be quantified by assaying plasma levels of desarginine FPB with antiserum R30 after (a) selective removal of cross-reacting FPB-containing fragments by bentonite adsorption, and $(b)$ complete conversion of FPB in the sample to desarginine FPB by incubation with carboxypeptide B (29). The plasmin-derived fibrinogen fragment, $B \beta 1-42$, was assayed as previously described (30) using an antiserum specific for $B \beta 1-42$ that does not cross-react with FPB or B $\beta 15-42$.

Purification of fibrinogen. Human fibrinogen (grade L, Kabi Vitrum) was rendered plasminogen-free by lysine Sepharose 4B affinity chromatography in the presence of aprotinin (100 Kallikrein inhibition units $[\mathrm{KIU}] / \mathrm{ml})$. The fibrinogen was then further purified as previously described $(31,32)$. The clottability of the purified material was 97\%. The absence of plasminogen was confirmed by incubating the material for $48 \mathrm{~h}$ at $37^{\circ} \mathrm{C}$ with streptokinase ( $3 \mathrm{U} / \mathrm{mg}$ fibrinogen). Electrophoresis of $50 \mu \mathrm{g}$ of reduced or unreduced sample on a $7.5 \%$ polyacrylamide gel revealed no evidence of degradation. Further, the absence of detectable $B \beta 1-42$ release from fibrinogen during the 48-h incubation period indicates that streptokinase treatment did not result in plasmin generation.

Cleavage of the $\mathrm{NH}_{2}$-terminal $\mathrm{A \alpha}$ - and B $\beta$-chain of fibrinogen by plasminogen activators. Experiments were performed at $37^{\circ} \mathrm{C} .1-\mathrm{ml}$ aliquots of heparinized plasma or purified fibrinogen (diluted to a concentration of $0.6 \mathrm{mg} / \mathrm{ml}$ in $0.1 \mathrm{M} \mathrm{NaCl}$ buffered with $0.05 \mathrm{M}$ Tris- $\mathrm{HCl}$ and containing $0.02 \%$ Tween 80 at $\mathrm{pH} 7.4$; TBS-Tween) were incubated at intervals from 2 to $120 \mathrm{~min}$ with $20 \mu \mathrm{l}$ of t-PA (rt-PA or melanoma t-PA). The t-PA concentration ranged from 0.25 to 50 $\mu \mathrm{g} / \mathrm{ml}$. Control samples were incubated with buffer in place of enzyme. At each time point, $100-\mu 1$ aliquots were removed and the reaction was stopped and the fibrinogen precipitated by the addition of $300 \mu \mathrm{l}$ ethanol followed by centrifugation at $4,000 \mathrm{~g}$ at $4^{\circ} \mathrm{C}$ for $20 \mathrm{~min}$. The ethanol supernatants were then evaporated to dryness in a Speed Vac Concentrator, reconstituted to original volume with distilled water and assayed for FPA and FPB immunoreactivity.

HPLC analysis of rt-PA proteolysis of fibrinogen. rt-PA mediated proteolysis of fibrinogen also was monitored using reverse-phase HPLC. $1 \mathrm{mg}$ of fibrinogen was suspended in $1 \mathrm{ml}$ of TBS. The fibrinogen was digested with $50 \mu \mathrm{g}$ of rt-PA at $37^{\circ} \mathrm{C}$ for $2 \mathrm{~h}$. At various times, $200-\mu l$ aliquots of the digestion mixture were removed and proteolysis was stopped by the addition of PMSF (final concentration, $5 \mathrm{mM}$ ). Undigested fibrinogen was then removed with Sep-Pak C18 cartridges (Waters Associates, Milford, MA). Adsorbed peptides were eluted with $3 \mathrm{ml}$ of $50 \%$ acetonitrile, evaporated to dryness and dissolved in $0.1 \%$ trifluoroacetic acid prior to HPLC analysis.

Analytic HPLC was performed using a liquid chromatograph (Beckman Instruments Inc., Palo Alto, CA) equipped with a model 421 A controller, two model 114 solvent delivery systems, a Beckman automatic injector model 504 and a data module (model CR1A; Shimadzu Scientific Instruments, Inc., Columbia, MD) plotter integrator. Peptides were monitored using a model 160 fixed wave length absorbance detector with a 214-nm filter. The column employed was an Ultrasphere ODS C18 (4.6 mm i.d., Beckman Instruments). Peptide samples were eluted from the column using gradients containing various concentrations of acetonitrile in the mobile phase. Solvents used in the chromatography included $0.1 \%$ trifluoroacetic acid (buffer A) and $0.1 \%$ trifluoroacetic acid containing $50 \%$ acetonitrile (buffer B). $1-\mathrm{ml}$ fractions were collected, evaporated to dryness, and then assayed for FPA and FPB immunoreactivity. 
Cleavage of FPA- and FPB-containing substrates by rt-PA. Experiments were performed at $37^{\circ} \mathrm{C}$ in TBS. Four synthetic FPA-containing analogues of the $\mathrm{NH}_{2}$-terminal region of the $\mathrm{A} \alpha$-chain of fibrinogen (A $\alpha 1-21, A \alpha 1-22, A \alpha 1-23$, and $A \alpha 1-28)$ and the FPB-containing peptide B $\beta 1-42$ were diluted in TBS to a final concentration of $10^{-6} \mathrm{M}$. $100-\mu \mathrm{l}$ aliquots of each peptide were incubated with $5 \mu \mathrm{ltt}-\mathrm{PA}(50 \mu \mathrm{g})$ for intervals ranging from 30 to $120 \mathrm{~min}$. In control experiments, the synthetic peptides were incubated with buffer in place of enzyme. At each time point, the reaction was terminated by the addition of PMSF (final concentration, $5 \mathrm{mM}$ ) and the samples were assayed for FPA or FPB immunoreactivity.

Proteolysis of FPA and FPB-containing substrates also was monitored using HPLC. $20 \mu \mathrm{g}$ of A $\alpha 1-21$ or B $\beta 1-42$ was suspended in $200 \mu \mathrm{l}$ of TBS. The peptides were incubated with $2 \mu \mathrm{g}$ of rt-PA at $37^{\circ} \mathrm{C}$ for $2 \mathrm{~h}$. In control experiments, the peptides were incubated with buffer in place of enzyme or with a mixture of enzyme and PMSF (final concentration, $5 \mathrm{mM}$ ). At the end of the incubation period, proteolysis was stopped by the addition of PMSF ( $5 \mathrm{mM}$, final concentration) and by passage of the sample over a C18 Sep-Pak cartridge. Adsorbed peptides were eluted with $3 \mathrm{ml}$ of $50 \%$ acetonitrile, evaporated to dryness, dissolved in $0.1 \%$ trifluoroacetic acid, and then subjected to HPLC analysis. 1-ml fractions were collected and assayed for FPA or FPB immunoreactivity.

\section{Results}

Fibrinopeptide levels in patients receiving $r t-P A$. The mean FPA level before rt-PA administration in five patients with radiographically documented venous thromboembolic disease was $0.6 \mathrm{nM}$ (Fig. 1). This value is within the reported normal

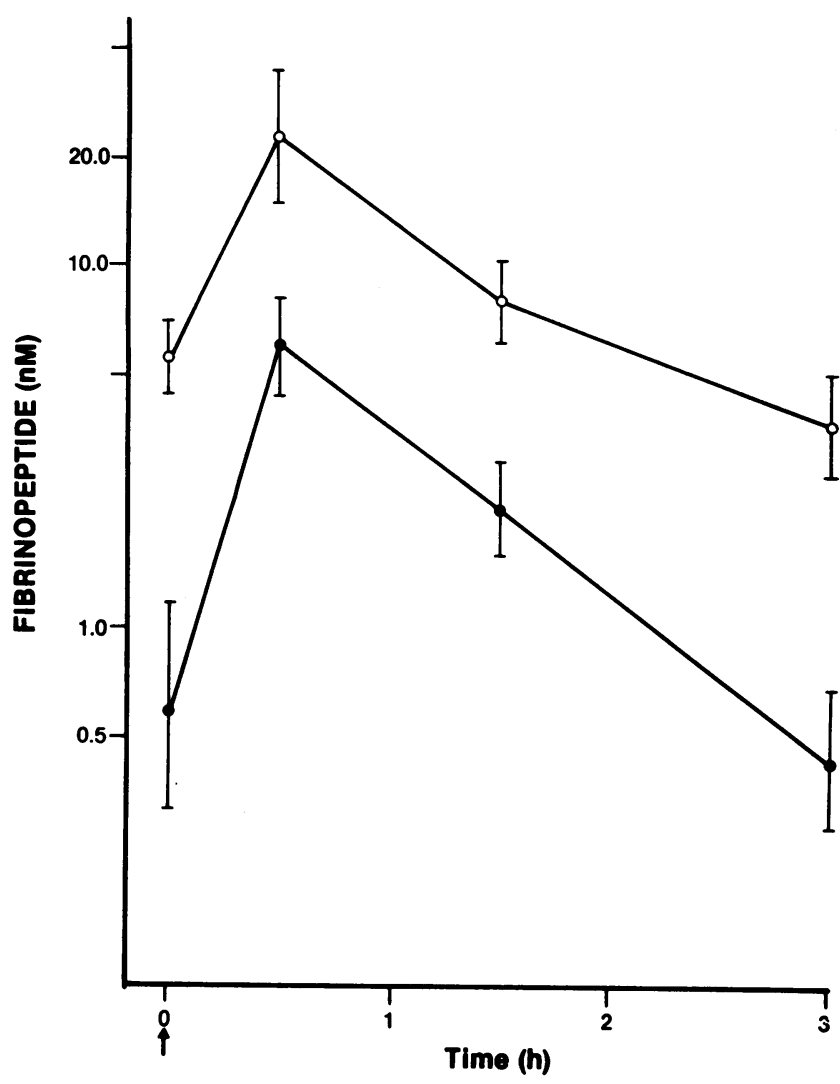

Figure 1. Plasma FPA levels (๑) and desarginine FPB (o) in five patients treated with a single bolus of rt-PA given at the time indicated by the arrow. The geometric mean values $\pm \mathrm{SE}$ are illustrated. range for FPA of $<1.3 \mathrm{nM}(24)$ and is consistent with previous reports of rapid normalization of FPA levels after heparin therapy for venous thromboembolic disease $(33,34)$. In contrast, the mean plasma value for desarginine FPB before rt-PA infusion was $5.6 \mathrm{nM}$, whereas normal levels are $<0.6 \mathrm{nM}$ (29).

Despite the concomitant administration of therapeutic doses of heparin, there was an increase in the mean levels of FPA (from 0.6 to $5.9 \mathrm{nM}$ ) and desarginine FPB (from 5.6 to $24.1 \mathrm{nM}) 30 \mathrm{~min}$ after rt-PA infusion. These differences are highly significant $(P<0.001$ and $P<0.01$, respectively) as determined by analysis of variance following log transformation of the data (35). Within $3 \mathrm{~h}$ of rt-PA administration the FPA and desarginine FPB levels had returned to the baseline values, although the mean desarginine FPB value remained considerably higher than that of FPA.

An additional patient with pulmonary embolism was treated with two bolus injections of rt-PA (data not shown). With each dose, there was a marked increase in the levels of FPA (from 0.1 to $2.7 \mathrm{nM}$, and from 0.9 to $3.6 \mathrm{nM}$, after the first and second dose, respectively) and desarginine FPB (from 1.7 to $9.4 \mathrm{nM}$, and from 3.2 to $12.3 \mathrm{nM}$, respectively) $10 \mathrm{~min}$ after the infusion. Thus, rt-PA infusion is associated with a prompt and marked increase in plasma FPA and desarginine FPB immunoreactivity that occurs despite concomitant heparin administration. Further, desarginine FPB levels are consistently higher than those of FPA, both before and after rt-PA infusion. These findings are not characteristic of thrombin action on fibrinogen $(19,20)$ and suggest that a different proteinase is responsible for fibrinopeptide release.

Plasma FPA and desarginine FPB immunoreactivity reflect free FPA and desarginine FPB, respectively. To prove that the increase in FPA and desarginine FPB immunoreactivity after rt-PA administration reflects free FPA and desarginine FPB, respectively, 1-ml aliquots of plasma ethanol supernatants were further processed by passage over Sep-Pak C18 cartridges. Adsorbed peptides were eluted with $3 \mathrm{ml}$ of $50 \%$ acetonitrile, evaporated to dryness, dissolved in $0.1 \%$ trifluoroacetic acid, and subjected to HPLC analysis. Fractions were then collected and assayed for FPA and desarginine FPB immunoreactivity. Synthetic and native FPA and desarginine FPB were used as internal standards. In each case, single peaks of FPA and desarginine FPB immunoreactivity that coeluted with their respective standards were detected. Thus, these studies demonstrate that the increase in FPA and desarginine FPB immunoreactivity after rt-PA administration reflects the free peptides.

Further evidence that increased FPA immunoreactivity reflects free FPA comes from studies of the immunochemical reactivity of the anti-FPA antiserum $R 2$ with a series of synthetic peptide analogues of the $\mathrm{NH}_{2}$-terminal region of the A $\alpha$-chain of fibrinogen (Table I). These investigations confirm previous reports demonstrating the specificity of this antiserum (25-27) and indicate that $\operatorname{Arg}(\mathrm{A} \alpha 16)$ is an essential component of the antigenic determinant of R2.

Plasminogen activator-mediated fibrinopeptide release from fibrinogen. To determine whether rt-PA has a direct effect on fibrinogen resulting in fibrinopeptide release, rt-PA was incubated with heparinized plasma (Fig. $2 A$ ) or with purified fibrinogen (Fig. $2 B$ ). This resulted in dose-dependent FPA and FPB release, and at each concentration of rt-PA used, the amount of FPB released was considerably higher than that of FPA. Thus, rt-PA cleaves both FPA and FPB from fibrinogen, 
Table I. Relative Molar Concentrations of FPA and Synthetic Peptide Analogues of the $\mathrm{NH}_{2}$-Terminal Region of the A $\alpha$-Chain of Fibrinogen Required for 50\% Inhibition of Binding of ${ }^{125}$ I-Tyrosyl-FPA by Antiserum R2

\begin{tabular}{cc}
\hline Peptide & $\begin{array}{c}\text { Relative molar } \\
\text { concentration }\end{array}$ \\
\hline FPA & \\
A $\alpha 1-16$ (FPA) & 1 \\
FPA-analogues & \\
A $\alpha 1-15$ & ND \\
A $\alpha 1-14$ & ND \\
A $\alpha 1-13$ & ND \\
A $\alpha 1-12$ & ND \\
FPA-containing analogues & \\
A $\alpha 1-18$ & 5,861 \\
A $\alpha 1-19$ & 1,021 \\
A $\alpha 1-20$ & 978 \\
A $\alpha 1-21$ & 1,266 \\
$A \alpha 1-22$ & 4,782 \\
A $\alpha 1-23$ & 3,681 \\
$A \alpha 1-28$ & ND
\end{tabular}

The $50 \%$ inhibitory concentration of FPA $(0.07 \pm 0.02 \mathrm{nM})$ was assigned an arbitrary value of unity. ND, no inhibition of binding was achieved with peptide concentrations of $10^{-6} \mathrm{M}$.

All experiments were done in triplicate.

and in plasma this activity is unaffected by heparin. Further, the pattern of rt-PA mediated fibrinopeptide release is different from that produced by thrombin $(19,20)$, and is characterized by cleavage of considerably more FPB than FPA.

The time course of fibrinopeptide release from purified fibrinogen illustrated in Fig. 3, demonstrates that the rate of

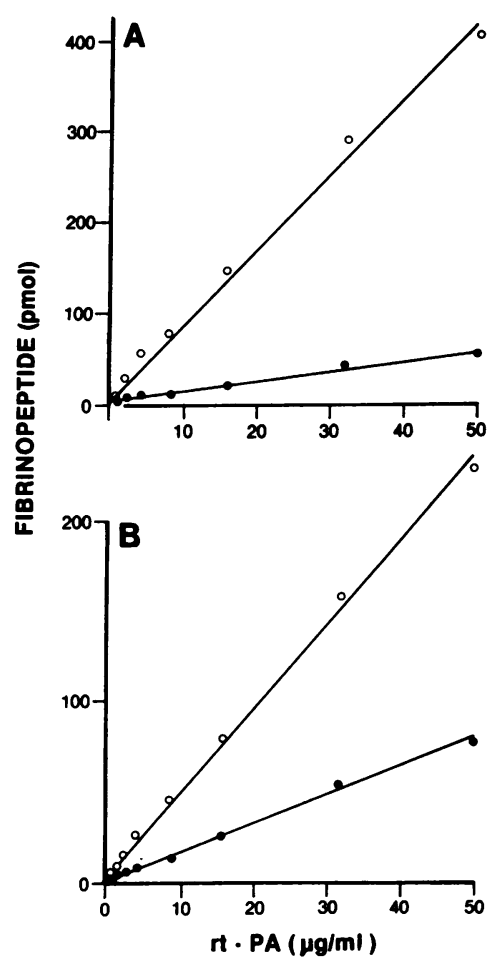

Figure 2. rt-PA-mediated fibrinopeptide release from fibrinogen in heparinized plasma or from purified fibrinogen. $(A)$ rt-PA, at the concentrations indicated, was incubated with heparinized plasma for $2 \mathrm{~h}$ at $37^{\circ} \mathrm{C}$, unreacted fibrinogen was precipitated with ethanol, and the supernatants were then assayed for FPA (๑) and desarginine FPB (O) immunoreactivity. $(B)$ rt-PA, at the concentrations indicated, was incubated with purified fibrinogen for $2 \mathrm{~h}$ at $37^{\circ} \mathrm{C}$, unreacted fibrinogen was precipitated with ethanol, and the supernatants were then assayed for FPA $(\bullet)$ and FPB (O) immunoreactivity.

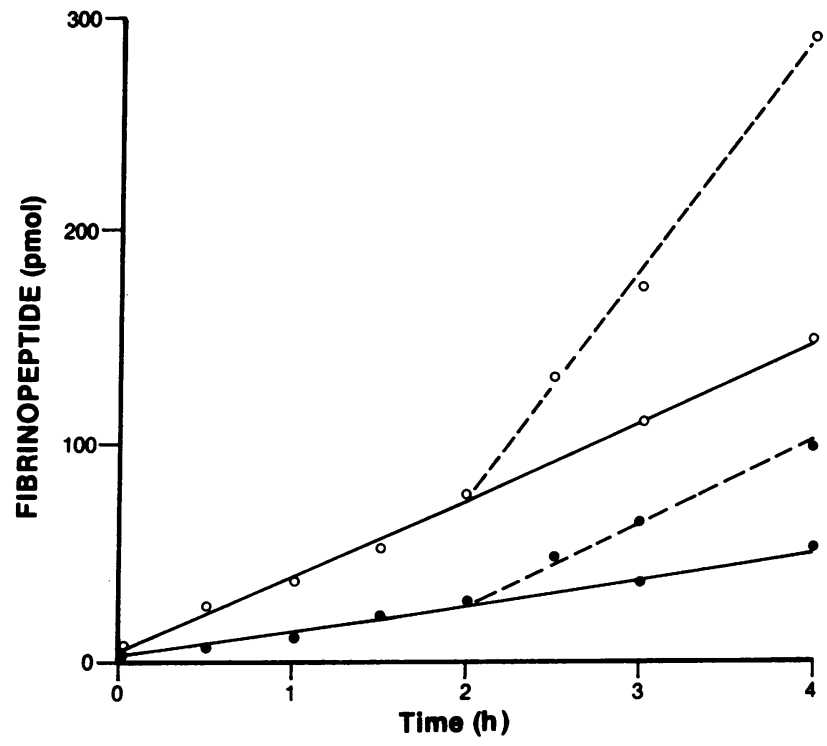

Figure 3. Time course of rt-PA mediated fibrinopeptide release from fibrinogen. Fibrinogen $(0.6 \mathrm{mg} / \mathrm{ml})$ was incubated with $\mathrm{rt}-\mathrm{PA}(16$ $\mu \mathrm{g} / \mathrm{ml}$ ) for the times indicated and the unreacted material was then precipitated with ethanol. The ethanol supernatants were then assayed for FPA (๑) and FPB (o) immunoreactivity. At $2 \mathrm{~h}$ incubation, additional rt-PA was added to a portion of the mixture. At the times shown, the fibrinogen was then precipitated with ethanol and FPA (•) and FPB (o) immunoreactivity was determined (broken lines).

FPB cleavage from fibrinogen is threefold faster than that of FPA. The delayed addition of more rt-PA further increases the rate of fibrinopeptide release, thereby confirming that these reactions are dependent on the enzyme concentration. No visible clot formation was detected over the 4-h incubation period, but during this time only $4.3 \%$ of the FPB and $1.4 \%$ of the FPA content of fibrinogen was released. It is estimated that at least $12 \%$ of the FPA must be released for coagulation to occur, while FPB cleavage is not a prerequisite for clot formation (36). Finally, SDS PAGE analysis of the time course of rt-PA mediated fibrinogenolysis did not show evidence of fibrinogen degradation, indicating that the lack of clot formation was not the result of progressive proteolysis of the fibrinogen molecule.

The pattern of fibrinopeptide release by rt-PA cloned in a human melanoma cell line and by melanoma cell t-PA was similar to that produced by the rt-PA cloned in a Chinese hamster ovarian cell line. Once again, both FPA and FPB were released but the rate of FPB release was faster than that of FPA. Fibrinopeptide release from fibrinogen is thus a characteristic of t-PA from a variety of sources.

HPLC analysis of $r t-P A$ mediated proteolysis of fibrinogen. To confirm that the increase in FPA and FPB immunoreactivity following rt-PA incubation with fibrinogen represented release of the free fibrinopeptides, proteolysis also was monitored using HPLC. The products of rt-PA mediated proteolysis were separated by reverse-phase HPLC (Fig. 4). Single immunoreactive peaks were observed that coeluted with synthetic or native FPA and FPB, respectively.

Effect of inhibitors and antibodies against thrombin and $t-P A$ on $r t-P A$ mediated fibrinopeptide release. To determine whether fibrinopeptide release by rt-PA was the result of a contaminating proteinase, the effect of a variety of inhibitors was investigated (Table II). Peptide release was unaffected by 




Figure 4. HPLC separation of peptides released during rt-PA proteolysis of fibrinogen. $(A)$ Approximately $5 \mu \mathrm{g}$ of FPA (peak 10.69) and FPB (peak 15.01) standards were injected onto the column using a flow rate of $1 \mathrm{ml} / \mathrm{min}$. 1-ml fractions were collected and assayed for FPA and FPB immunoreactivity. (B) Fibrinogen was digested with rt-PA for $2 \mathrm{~h}$ at $37^{\circ} \mathrm{C}$. Unreacted fibrinogen was removed by passage over a C18 cartridge and adsorbed peptides were eluted with $3 \mathrm{ml}$ of $50 \%$ acetonitrile. Approximately $20 \mu \mathrm{l}$ of the digestion mixture was then injected onto the column using the same flow rate. 1-ml fractions were collected and assayed for FPA and FPB immunoreactivity.

hirudin, thus indicating that thrombin is not responsible for this activity. Aprotinin, a plasmin inhibitor, had no effect on fibrinopeptide release, while epsilon-amino caproic acid (EACA) partially blocked this activity. In contrast, peptide release was completely inhibited by D-Phe-Pro- $\mathrm{ArgCH} \mathrm{Cl}_{2} \mathrm{Cl}$ and by PMSF. D-Phe-Pro- $\mathrm{ArgCH} \mathrm{Cl}_{2} \mathrm{Cl}$, a potent inhibitor of thrombin (37), also acts as an irreversible inhibitor of t-PA (38). These studies thus indicate that fibrinopeptide release is mediated by a serine proteinase other than thrombin or plasmin. Further, the interaction between fibrinogen and rt-PA depends on the lysine-binding sites of rt-PA since fibrinopeptide release is partially inhibited by EACA.

There was virtually no fibrinopeptide release when fibrinogen was incubated with rt-PA that had been pretreated with $20 \mu \mathrm{g} / \mathrm{ml}$ of ESP 2 (Table III), a monoclonal antibody against t-PA that abolishes its amidolytic and fibrinolytic activity (21). In contrast, pretreatment of rt-PA with a polyclonal monospe-

Table II. Effect of Inhibitors on rt-PA-Mediated Fibrinopeptide Release from Fibrinogen

\begin{tabular}{|c|c|c|}
\hline Inhibitor & FPA & FPB \\
\hline & pmol & pmol \\
\hline None & $26.5 \pm 8.0$ & $90.4 \pm 9.3$ \\
\hline Hirudin $(1 \mathrm{U} / \mathrm{ml})$ & $26.8 \pm 9.4$ & $92.4 \pm 4.5$ \\
\hline Trasylol $(100 \mathrm{KIU} / \mathrm{ml})$ & $25.2 \pm 6.1$ & $89.7 \pm 5.4$ \\
\hline EACA $(5 \mathrm{mM})$ & $12.2 \pm 4.2$ & $36.6 \pm 5.7$ \\
\hline D-Phe-Pro-ArgCH${ }_{2} \mathrm{Cl}(10 \mu \mathrm{M})$ & $0.4 \pm 0.3$ & $1.3 \pm 0.5$ \\
\hline PMSF (5 mM) & $0.2 \pm 0.4$ & $0.4 \pm 0.2$ \\
\hline
\end{tabular}

The results shown are the means \pm SD from four separate experiments. Fibrinogen $(0.6 \mathrm{mg} / \mathrm{ml})$ was incubated with $\mathrm{rt}-\mathrm{PA}(16 \mu \mathrm{g} / \mathrm{ml})$ for $2 \mathrm{~h}$ at $37^{\circ} \mathrm{C}$ in the presence or absence of inhibitors. The reactions were stopped and the fibrinogen precipitated by the addition of ethanol, and the ethanol supernatants were then assayed for FPA and FPB immunoreactivity.
Table III. Effect of Antibodies against Thrombin and t-PA on rt-PA-mediated Fibrinopeptide Release from Fibrinogen

\begin{tabular}{lrr}
\multicolumn{1}{c}{ Antibody } & \multicolumn{1}{c}{ FPA } & FPB \\
\hline & pmol & pmol \\
None & $26.5 \pm 8.0$ & $90.4 \pm 9.3$ \\
Antithrombin IgG & $28.7 \pm 8.9$ & $95.3 \pm 8.0$ \\
Anti-t-PA IgG & $0.1 \pm 0.2$ & $1.6 \pm 1.3$
\end{tabular}

The results shown are the means \pm SD from four separate experiments. Fibrinogen $(0.6 \mathrm{mg} / \mathrm{ml})$ was incubated with $\mathrm{rt}-\mathrm{PA}(16 \mu \mathrm{g} / \mathrm{ml})$ for $2 \mathrm{~h}$ at $37^{\circ} \mathrm{C}$ in the presence and absence of antibodies against thrombin or t-PA. The reactions were stopped and the fibrinogen precipitated by the addition of ethanol and the ethanol supernatants were then assayed for FPA and FPB immunoreactivity.

cific antithrombin IgG or with control sheep or mouse IgG (data not shown) had no effect on its fibrinogenolytic activity. Thus, rt-PA is the enzyme responsible for fibrinopeptide release.

Effect of inhibitors and antibodies against thrombin and $r t-P A$ on $F P A$ release by a mixture of $r t-P A$ and thrombin. To further exclude the possibility that rt-PA is contaminated with trace amounts of thrombin, the effect of a variety of inhibitors on fibrinopeptide release mediated by a mixture of thrombin and rt-PA was investigated (Table IV). Incubation of fibrinogen $(0.6 \mathrm{mg} / \mathrm{ml})$ with $\alpha$-thrombin $\left(4.0 \times 10^{-4} \mathrm{U} / \mathrm{ml}\right)$ resulted in FPA release similar in amount to that produced by $16 \mu \mathrm{g} / \mathrm{ml}$ of rt-PA (28.9 and $26.5 \mathrm{pmol}$, respectively). When a mixture of thrombin and rt-PA was incubated with fibrinogen there was an additive effect on FPA release. The addition of hirudin or a monospecific antithrombin IgG decreased by approximately half the amount of FPA released by the proteinase mixture. ESP 2, a monoclonal antibody against t-PA, had a similar effect on peptide release. In contrast, the addition of PMSF or D-Phe-Pro-ArgCH $\mathrm{Cl}_{2} \mathrm{Cl}$ totally blocked FPA release. These studies thus confirm that rt-PA mediated FPA release is not the result of contaminating thrombin.

Table IV. Effect of Inhibitors and Antibodies against Thrombin and $t-P A$ on FPA Release by a Mixture of Thrombin and rt-PA

\begin{tabular}{lc}
\multicolumn{1}{c}{ Inhibitor } & FPA \\
\hline & pmol \\
None & 51.9 \\
Hirudin $(1 \mathrm{U} / \mathrm{ml})$ & 23.7 \\
Antithrombin IgG & 22.6 \\
Anti-t-PA IgG & 24.3 \\
D-Phe-Pro-ArgC ${ }_{2} \mathrm{Cl}(10 \mu \mathrm{M})$ & 0.1 \\
PMSF $(5 \mathrm{mM})$ & 0.3
\end{tabular}

Results shown represent the mean data from two separate experiments. Fibrinogen $(0.6 \mathrm{mg} / \mathrm{ml})$ was incubated with a mixture of $\mathrm{rt}-\mathrm{PA}(16 \mu \mathrm{g} / \mathrm{ml})$ and $\alpha$-thrombin $\left(4.04 \times 10^{-4} \mathrm{U} / \mathrm{ml}\right)$ for $2 \mathrm{~h}$ at $37^{\circ} \mathrm{C}$ in the presence and absence of inhibitors and antibodies against thrombin or t-PA. The reactions were stopped and the fibrinogen precipitated by the addition of ethanol, and the ethanol supernatants were then assayed for FPA immunoreactivity. 
rt-PA mediated peptide release from FPA- and FPB-containing substrates. To further explore the specificity of rt-PA for the $\mathrm{A} \alpha$ 16-17 bond on the $\mathrm{NH}_{2}$-terminal region of the $\mathrm{A} \alpha$ chain of fibrinogen, and the $\mathrm{B} \beta 14-15$ bond on the $\mathrm{B} \beta$-chain, rt-PA was incubated with FPA or FPB-containing substrates. Incubation of rt-PA with A $\alpha 1-21$ and other FPA-containing substrates (A $\alpha 1-22, A \alpha 1-23$, and $A \alpha 1-28)$ or with $B \beta 1-42$ resulted in an increase in FPA or FPB immunoreactivity, respectively (data not shown). To confirm that the increase in fibrinopeptide immunoreactivity represented release of free FPA or FPB, aliquots of the incubation mixtures were analyzed by HPLC using synthetic FPA or FPB as internal standards. Fractions were collected and assayed for FPA and FPB immunoreactivity. In the case of rt-PA proteolysis of A $\alpha 1-21$, a single peak of FPA immunoreactivity was detected that coeluted with synthetic FPA (Fig. 5). In contrast, proteolysis of $\mathrm{B} \beta 1-42$ yielded a single peak of FPB immunoreactivity that coeluted with synthetic FPB (data not shown). These studies confirm the specificity of rt-PA for the thrombin cleavage sites.

\section{Discussion}

Our findings confirm a previous report that rt-PA administration is associated with an increase in plasma FPA levels (18) and demonstrate that this increase occurs despite concomitant heparin administration. We have extended these observations by demonstrating that plasma values of desarginine FPB also are elevated after rt-PA infusion, and that the levels of this peptide are higher than those of FPA, both before and after rt-PA administration (Fig. 1). Finding increased desarginine FPB levels before rt-PA infusion is unexpected since the patients were receiving heparin therapy and plasma FPA values were within the normal range. This suggests that an enzyme other than thrombin is responsible for FPB release. The finding that desarginine FPB levels remain higher than those of FPA after rt-PA infusion further supports this concept since this pattern is not characteristic of thrombin action on fibrinogen.

Confirmation that FPA and desarginine FPB immunoreactivity in patient samples represented the free peptides (and not some other cross-reacting fibrinogen-derived fragments) came from the HPLC demonstration that the immunoreactive fractions coeluted with native or synthetic FPA and desarginine FPB, respectively. Further, epitope mapping studies (Table I) validate previous reports (25-27) that the FPA antiserum $R 2$ is specific for FPA and demonstrate that $\mathrm{Arg}(\mathrm{A} \alpha 16)$ is an essential component of the antigenic determinant.

To explore the possibility that the increase in fibrinopeptide values after rt-PA administration results from a direct effect of rt-PA on fibrinogen resulting in peptide release, rt-PA was incubated with heparinized plasma or purified fibrinogen and release of FPA and FPB was determined (Fig. 2). There was dose-dependent release of both fibrinopeptides and at each rt-PA concentration, the amount of FPB released was considerably more than that of FPA. Confirmation that the increase in FPA and FPB immunoreactivity reflects release of the free peptides from fibrinogen comes from the HPLC demonstration that the immunoreactive peaks in the digestion mixture coeluted with native or synthetic FPA and FPB, respectively (Fig. 4).

Several lines of evidence indicate that rt-PA mediated fibrinopeptide release is not the result of contaminating throm- bin. First, the pattern of rt-PA-mediated fibrinopeptide release is different from that produced by thrombin. Whereas rt-PA produces more rapid release of FPB (Figs. 2 and 3), thrombin results in more rapid FPA release from fibrinogen $(19,20)$. Second, rt-PA-mediated fibrinopeptide release occurs in the presence of the thrombin inhibitors, heparin (Fig. $2 A$ ) and hirudin (Table II), and release is unaffected by a monospecific antithrombin IgG (Table III). Third, fibrinopeptide release mediated by a mixture of thrombin and rt-PA is decreased by half following the addition of hirudin, an antithrombin IgG or a monoclonal antibody against t-PA (Table IV). Inhibiting that component of fibrinopeptide release induced by thrombin (with hirudin or with an antithrombin IgG) thus has no effect on the rt-PA-mediated component of peptide release. Finally, plasmin is not responsible for fibrinopeptide release since aprotinin has no effect on this activity (Table II). Further, plasmin releases $B \beta 1-42$ from fibrinogen (30), rather than FPA or FPB, and no B $\beta 1-42$ was detected in the digestion mixture.

The evidence that t-PA cleaves FPA and FPB from fibrinogen comes from the demonstration that immunodepletion of rt-PA using a monoclonal antibody against t-PA abolishes rt-PA mediated fibrinopeptide release (Table III). Further, rt-PA releases FPA and FPB from A $\alpha 1-21$ (Fig. 5) and B $\beta 1-42$, respectively, thereby confirming the specificity of rt-PA for the thrombin cleavage sites on FPA and FPB-containing substrates. Finally, fibrinopeptide release is effected by rt-PA cloned from two different cell lines and by human melanoma cell derived t-PA, indicating that this activity is a function of t-PA derived from a variety of sources.

The interaction between rt-PA and fibrinogen that results in fibrinopeptide release depends on the active-site serine of rt-PA since peptide release is inhibited by PMSF (Table II), which presumably acts by modifying this region of the mole-

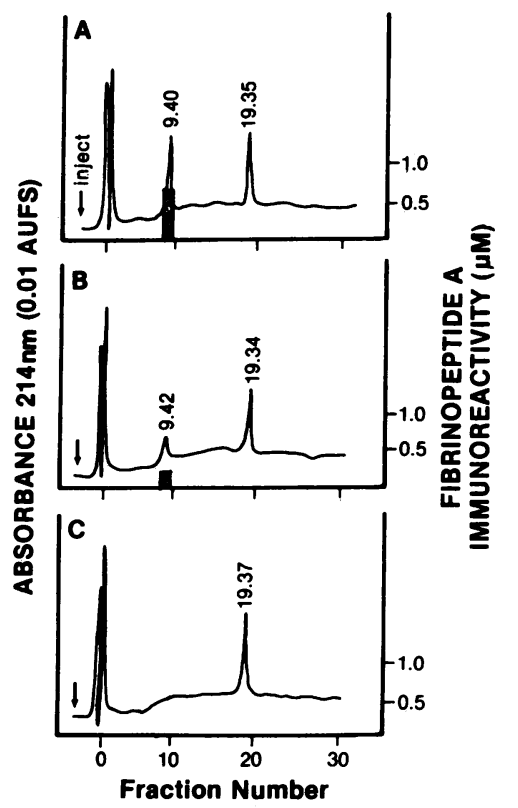

Figure 5. HPLC analysis of rt-PA mediated proteolysis of $A \alpha 1-21$. (A) Approximately $5 \mu \mathrm{g}$ of FPA (peak 9.40) and A $\alpha 1$-21 (peak 19.35) standards were injected onto the column using a flow rate of $1 \mathrm{ml} / \mathrm{min}$. 1 -ml fractions were collected and assayed for FPA immunoreactivity. (B) A $\alpha 1-21$ was digested with rt-PA for 2 $\mathrm{h}$ at $37^{\circ} \mathrm{C}$. Approximately $20 \mu \mathrm{l}$ was injected onto the column using the same flow rate. 1-ml fractions were collected and assayed for FPA immunoreactivity. (C) A $\alpha 1-21$ was digested with rt-PA for $2 \mathrm{~h}$ at $37^{\circ} \mathrm{C}$ in the presence of PMSF ( 5 $\mathrm{mM}$, final concentration). Approximately 20 $\mu l$ was injected onto the column as described above. 
cule (39). The active site histidine also is important since fibrinopeptide release is abolished by D-Phe-Pro- $\mathrm{ArgCH} \mathrm{Cl}_{2} \mathrm{Cl}$, which irreversibly binds to this site with a reported rate constant of $300 \mathrm{M}^{-1} \mathrm{~s}^{-1}$ (38). Further evidence for involvement of this latter site comes from the demonstration that a monoclonal antibody against t-PA (ESP 2), which is reported to interact with the active-site histidine (21), completely blocks rt-PA-mediated fibrinopeptide release. Finally, the interaction between fibrinogen and rt-PA depends, at least to some extent, on rt-PA binding via its lysine-binding sites since EACA partially inhibits rt-PA mediated fibrinopeptide release from fibrinogen.

These studies demonstrate that t-PA has a direct thrombin-like effect on fibrinogen resulting in fibrinopeptide release. Unlike thrombin however, t-PA releases FPB more rapidly than FPA (Figs. 2 and 3). An important question is how the in vitro findings relate to the changes in fibrinopeptide levels that occur in patients treated with rt-PA. Since the values of desarginine FPB are higher than those of FPA (both before and after rt-PA administration) it is unlikely that these changes are the result of thrombin action on fibrinogen. Accordingly, a different proteinase must be responsible. Certainly t-PA is a possible candidate because it preferentially cleaves FPB from fibrinogen. Further, the elevated desarginine FPB levels before rt-PA infusion may reflect the action of endogenous $t-P A$ released from endothelial cells in response to high local concentrations of thrombin $(40,41)$ or stimuli associated with venous stasis (42). The neutrophil proteinase, elastase, also may contribute since this enzyme is released from neutrophils during the blood coagulation process (43) and has the potential to attack the $\mathrm{NH}_{2}$-terminal region of the $\mathrm{B} \beta$-chain of fibrinogen resulting in increased desarginine FPB immunoreactivity (44) without an increase in FPA (23).

The extent of elevation and the persistent increase in fibrinopeptide levels after rt-PA administration is difficult to explain given the short half-lives of t-PA $(45,46)$ and the fibrinopeptides $(24,29)$, and the relatively slow rates of rt-PAmediated fibrinopeptide release in vitro. The binding of functionally active t-PA to endothelial cells (47) however, may serve to localize and protect the enzyme from its inhibitors thereby prolonging its duration of action and increasing its enzymatic potential. This possibility deserves further study.

In summary, these studies demonstrate that t-PA has enzymatic specificity for a macromolecular substrate other than plasminogen and cleaves the thrombin susceptible bonds on fibrinogen. Accordingly, plasma FPA and desarginine FPB levels are not specific markers of thrombin action on fibrinogen in patients receiving thrombolytic therapy with rt-PA.

\section{Acknowledgments}

The authors wish to thank Drs. J. Hirsh and J. Henkin for their excellent advice and encouragement, Drs. J. Owen and E. Regoeczi for their helpful comments, and S. Crnic for preparing the manuscript. Dr. Eckhardt is affiliated with the Department of Medicine, Justus Liebig University, Giessen, FRG

This investigation was supported by grants from the Ontario Heart and Stroke Foundation and the Medical Research Council of Canada. Dr. Weitz is a Scholar of the Heart and Stroke Foundation of Ontario.

\section{References}

1. Rijken, D. C., M. Hoylaerts, and D. Collen. 1982. Fibrinolytic properties of one-chain human extrinsic (tissue-type) plasminogen activator. J. Biol. Chem. 257:2920-2925.
2. Rijken, D. C., and D. Collen. 1981. Purification and characterization of the plasminogen activator secreted by human melanoma cells in culture. J. Biol. Chem. 256:7035-7041.

3. Hoylaerts, M., D. C. Rijken, H. R. Lijnen, and D. Collen. 1982. Kinetics of the activation of plasminogen by human tissue plasminogen activator. Role of fibrin. J. Biol. Chem. 257:2912-2919.

4. Ranby, M. 1982. Studies on the kinetics of plasminogen activation by tissue plasminogen activator. Biochim. Biophys. Acta. 704:461-469.

5. Topol, E. J., W. R. Bell, and M. L. Weisfeldt. 1985. Coronary thrombolysis with recombinant tissue-type plasminogen activator. A hematologic and pharmacologic study. Ann. Intern. Med. 103:837843.

6. Van de Werf, F., P. A. Ludbrook, S. R. Bergmann, A. J. Tiefenbrunn, K. A. Fox, H. de Geest, M. Verstraete, D. Collen, and B. E. Sobel. 1984. Coronary thrombolysis with tissue-type plasminogen activator in patients with evolving myocardial infarction. $N$. Engl. J. Med. 310:609-613.

7. TIMI Study Group. 1985. The thrombolysis in myocardial infarction (TIMI) trial: phase 1 findings. N. Engl. J. Med. 312:932-936.

8. Verstraete, M., M. Bory, D. Collen, R. Erbel, R. J. Lennane, D. G. Mathey, H. R. Michels, M. Schartl, R. Uebis, R. Bernard, R. W. Brower, D. P. deBono, W. Huhmann, J. Lubsen, J. Meyer, W. Rutsch, W. Schmidt, and R. von Essen. 1985. Randomized trial of intravenous recombinant tissue type plasminogen activator versus intravenous streptokinase in acute myocardial infarction. Lancet. i:842-847.

9. Owen, J., K. D. Friedman, B. A. Grossman, C. Wilkins, A. D. Berke, and E. R. Powers. 1987. Quantitation of fragment X formation during thrombolytic therapy with streptokinase or tissue plasminogen activator. J. Clin. Invest. 79:1642-1647.

10. Sobel, B. E., R. W. Gross, and A. K. Robison. 1984. Thrombolysis, clot selectivity, and kinetics. Circulation. 70:160-164.

11. Noe, D. A., and W. R. Bell. 1987. A kinetic analysis of fibrinogenolysis during plasminogen activator therapy. Clin. Pharmacol. Ther. 41:297-303.

12. Collen, D., E. J. Topol, A. J. Tiefenbrunn, H. K. Gold, M. L. Weisfeldt, B. E. Sobel, R. C. Leinback, J. A. Brinker, P. A. Ludbrook, T. Yasuda, B. H. Bulkey, A. K. Robison, A. M. Hutter, W. R. Bell, J. J. Spadaro, B. A. Khaw, and E. B. Grossbard. 1984. Coronary thrombolysis with recombinant human tissue type plasminogen activator: a prospective randomized placebo controlled trial. Circulation. 70:1012-1017.

13. Williams, D. O., J. Borer, E. Braunwald, J. H. Chesebro, L. S. Cohen, J. Dalen, H. T. Dodge, C. K. Francis, G. Knatterud, P. Ludbrook, J. E. Markis, H. Mueller, P. Desvigne-Nickens, E. R. Pasamani, E. Powers, A. K. Rao, R. Roberts, A. Ross, T. Ryant, B. E. Sobel, M. Winniford, and B. Zaret. 1986. Intravenous recombinant tissue type plasminogen activator in patients with acute myocardial infarction. A report from the NHLBI thrombolysis in myocardial infarction trial. Circulation. 73:338-346.

14. Gold, K. H., R. C. Leinbach, H. D. Garabedian, T. Yasuda, J. A. Johns, E. B. Grossbard, I. Palacios, and D. Collen. 1986. Acute coronary reocclusion after thrombolysis with recombinant human tissue type plasminogen activator: prevention by a maintenance infusion. Circulation. 73:347-352.

15. Cheseboro, J. H., G. Knatterud, R. Roberts, J. Borer, L. S. Cohen, J. Dalen, H. T. Dodge, C. K. Francis, D. Hillis, P. Ludbrook, J. E. Markis, H. Mueller, E. R. Passamani, E. R. Powers, A. K. Rao, T. Robertson, A. Ross, T. J. Ryan, B. E. Sobel, T. Willerson, D. O. Williams, and E. Braunwald. 1987. Thrombolysis in myocardial infarction (TIMI) Trial, Phase I: a comparison between intravenous tissue plasminogen activator and intravenous streptokinase. Clinical findings through hospital discharge. Circulation. 76:142-154.

16. Harrison, D. G., D. W. Ferguson, S. M. Collins, D. J. Skorton, E. E. Ericksen, J. M. Kioschos, M. L. Marcus, and C. W. White. 1984. Rethrombosis after reperfusion with streptokinase: importance of geometry or residual lesions. Circulation. 69:991-999.

17. Eisenberg, P. R., L. Sherman, M. Rich, D. Schwartz, K. 
Schechtman, E. M. Geltman, B. E. Sobel, and A. S. Jaffe. 1986. Importance of continued activation of thrombin reflected by fibrinopeptide A to the efficacy of thrombolysis. J. Am. Coll. Cardiol. 7:12551262.

18. Owen, J., K. D. Friedman, B. A. Grossman, C. Wilkins, A. D. Berke, and E. R. Powers. 1988. Thrombolytic therapy with tissue plasminogen activator or streptokinase induces transient thrombin activity. Blood. 72:616-620.

19. Blomback, B., and A. Vestermark. 1958. Isolation of fibrinopeptides by chromatography. Arkiv. Kemi. 12:173-182.

20. Bilizekian, S. B., H. L. Nossel, V. P. Butler Jr., and R. E. Canfield. 1975. Radioimmunoassay of fibrinopeptide $B$ and kinetics of fibrinopeptide cleavage by different enzymes. J. Clin. Invest. 56:438445.

21. MacGregor, I. R., L. R. Micklem, K. James, and D. S. Pepper. 1985. Characterisation of epitopes on human tissue plasminogen activator recognized by a group of monoclonal antibodies. Thromb. Haemostasis. 53:45-50.

22. Marglin, A., and R. B. Merrifield. 1970. Chemical synthesis of peptides and proteins. Annu. Rev. Biochem. 39:841-866.

23. Weitz, J. I., S. L. Landman, K. A. Crowley, S. Birken, and F. Morgan. 1986. Development of an assay for in vivo neutrophil elastase activity: increased elastase activity in patients with alpha 1-proteinase inhibitor deficiency. J. Clin. Invest. 78:155-162.

24. Nossel, H. L., I. Yudelman, R. E. Canfield, V. P. Butler Jr., K. Spanondis, G. D. Wilner, and G. D. Qureshi. 1974. Measurement of fibrinopeptide A in human blood. J. Clin. Invest. 54:43-53.

25. Canfield, R. E., J. Dean, H. L. Nossel, V. P. Butler, Jr., and G. D. Wilner. 1976. Reactivity of fibrinogen and fibrinopeptide A containing fragments with antisera to fibrinopeptide A. Biochemistry. 15:1203-1209.

26. Wilner, G. D., H. L. Nossel, R. E. Canfield, and V. P. Butler, Jr. 1976. Immunochemical studies of human fibrinopeptide A using synthetic peptide homologues. Biochemistry. 15:1209-1213.

27. Nossel, H. L., V. P. Butler Jr., G. D. Wilner, R. E. Canfield, and E. J. Harfenist. 1976. Specificity of antisera to human fibrinopeptide A used in clinical fibrinopeptide A assays. Thromb. Haemostasis. 35:101-109.

28. LaGamma, K. S., and H. L. Nossel. 1978. The stability of fibrinopeptide B immunoreactivity in blood. Thromb. Res. 12:447454.

29. Eckhardt, T., H. L. Nossel, A. Hurlet-Jensen, K. S. LaGamma, J. Owen, and M. Auerbach. 1981. Measurement of desarginine fibrinopeptide B in human blood. J. Clin. Invest. 67:809-816.

30. Weitz, J. I., J. A. Koehn, R. E. Canfield, S. L. Landman, and R. Friedman. 1986. Development of a radioimmunoassay for the fibrinogen-derived fragment B $\beta 1-42$. Blood. 67:1014-1022.
31. Chibber, B. A. K., D. G. Deutsch, and E. T. Mertz. 1974. Plasminogen. Methods Enzymol. 34:424-432.

32. Finlayson, J. S. 1968. Chromatographic purification of fibrinogen. In Fibrinogen. K. Laki, editor. Marcel Dekker, Inc., New York. 39-59.

33. Peuscher, F. W., W. G. van Aken, N. T. Flier, E. A. Stoepmanvan Dalen, T. M. Cremer Grote, and J. A. van Mourik. 1980. Effect of anticoagulant treatment measured by fibrinopeptide A (FPA) in patients with venous thromboembolism. Thromb. Res. 18:33-43.

34. Yudelman, I., and J. Greenberg. 1982. Factors affecting fibrinopeptide-A levels in patients with venous thromboembolism during anticoagulant therapy. Blood. 59:787-792.

35. Sokal, R. R., and F. J. Rohlf. 1969. Biometry: The Principle and Practise of Statistics in Biological Research. W. H. Freeman and Co., San Francisco, CA. 53-59.

36. Herzig, R. H., O. D. Ratnoff, and J. R. Shainoff. 1970. Studies on a procoagulant fraction of southern copperhead snake venom: The preferential release of fibrinopeptide B. J. Lab. Clin. Med. 76:451-465.

37. Kettner, C., and E. Shaw. 1979. D-Phe-Pro-ArgCH ${ }_{2} \mathrm{Cl}$. A selective affinity label for thrombin. Thromb. Res. 14:969-973.

38. Rijken, D. C., M. Hoylaerts, and D. Collen. 1982. Fibrinolytic properties of one-chain and two-chain human extrinsic (tissue-type) plasminogen activator. J. Biol. Chem. 257:2920-2925.

39. Lundblad, R. C. 1971. A rapid method for the purification of bovine thrombin and the inhibition of the purified enzyme with phenylmethylsulfonyl fluoride. Biochemistry. 10:2051-2056.

40. Loskutoff, D. 1979. Effect of thrombin on the fibrinolytic activity of cultured bovine endothelial cells. J. Clin. Invest. 64:329-332.

41. Levin, E. G., U. Marzec, J. Anderson, and L. A. Harker. 1984. Thrombin stimulates tissue plasminogen activator release from cultured human endothelial cells. J. Clin. Invest. 74:1988-1996.

42. Kluft, C. 1979. Studies on the fibrinolytic system in human plasma. Thromb. Haemostasis. 41:365-383.

43. Plow, E. F. 1982. Leukocyte elastase release during blood coagulation. A potential mechanism for activation of the alternative fibrinolytic pathway. J. Clin. Invest. 69:546-572.

44. Eckhardt, T., S. Haas, B. Lange, and H. Pfeiffer. 1987. Measurement of elastase-induced fibrinogen derived peptides in vitro. Thromb. Haemostasis. 58:104. (Abstr.)

45. Nilsson, T., P. Wallen, and G. Mellbring. 1984. In vivo metabolism of human tissue-type plasminogen activator. Scand. J. Haematol. 33:49-53.

46. Verstraete, M., H. Bounameaux, F. de Cock, F. Van de Werf, and D. Collen. 1985. Pharmacokinetics and systemic fibrinogenolytic effects of recombinant human tissue plasminogen activator (rt-PA) in humans. J. Pharmacol. Exp. Ther. 235:1731-1739.

47. Hajjar, K. A., N. M. Hamel, P. C. Harpel, and R. L. Nachman. 1987. Binding of tissue plasminogen activator to cultured human endothelial cells. J. Clin. Invest. 80:1712-1719. 